Pobrane z czasopisma New Horizons in English Studies http://newhorizons.umcs.pl Data: 26/04/2023 04:50:43

New Horizons in English Studies 4/2019

\title{
REVIEW
}

$\infty$

\author{
Klaudia Gąsior \\ Maria Curie-SkŁodowska University (UMCS) in Lublin \\ KLAUDIA.GASIOR@ONET.EU
}

\section{Listen, Speak, Read and Write!: The Quaternary Approach as the Future of Language and Non-language Courses}

\author{
Daszkiewicz, Michał, Wenzel, Ryszard \& Monika \\ Kusiak-Pisowacka. Educational Role of Language Skills. Gdańsk: \\ Wydawnictwo Uniwersytetu Gdańskiego. 2018, 199 pp.
}

Language skills are believed to shape who we are and how we are perceived by other people. Since "we look at people and frequently describe them in terms of how much they speak, how extensively they read, how well they write or how attentively they listen", four language skills can be regarded as the key factors facilitating effective interpersonal communication (Daszkiewicz et al. 2018: 18). However, the problem with listening, speaking, reading and writing is that they are frequently taken for granted in language education owing to the fact that once acquired by students, they are not further worked on in instructed settings. Even though language skills, in spite of their considerable potential to contribute to learners' overall cognitive development, have been mostly unnoticed in the field of Glottodidactics, the publication Educational Role of Language Skills proves that they do provide, maintain and strengthen the link between subjects from the curriculum and students' cognition or worldview.

The authors of Educational Role of Language Skills, Michał Daszkiewicz, Ryszard Wenzel and Monika Kusiak-Pisowacka, participated in an annual international interdisciplinary conference Educational Role of Language which has been organized since 
2016. The researchers' efforts to appreciate the significance of language skills resulted in the publication of the book under discussion which puts listening, speaking, reading and writing into the centre of readers' attention. The seminal work has been divided into two parts. The first consists of an Introduction followed by two subchapters which are devoted to the detailed discussion of selected aspects concerning current trends in education. The latter contains four sections, each of which discusses one of the four language skills from the perspective of Learning to (...) and (...) to Learn approaches. The organisation of the second part of the book follows a traditional division of language skills into that of reception and production, starting with the discussion of listening and reading followed by speaking and writing.

In the first section of Part One the authors acknowledge a high position of language, noting that the application of terms used in language education to other non-language subjects is of high utility. They maintain that the lack of language-related terminology may lead to situations in which people are not able to see the connection between the language used by them and their world knowledge (Daszkiewicz et al. 2018: 21). The concept that the writers find central to the discussion of the educational role of language skills is the so-called glottodidactic paradigm which encompasses concepts from such disciplines as psychology, sociolinguistics and pedagogy (Daszkiewicz et al. 2018: 22). For the purpose of the publication in question the authors limit themselves to the discussion of the key ideas from axiological, psychomotor, affective and cognitive domains. They also made it clear that the organisation of all stages of education around the glottodidactic concepts may contribute not only to a better diagnosis of problems that learners and teachers face, but also to a more adequate provision of solutions on personal, that is either student- or teacher-oriented, and textual levels concerning language production and reception.

In the second section of Part One the discussion centres around explaining the phenomena of learning to listen, read, speak and write. To be more precise, the differences between genuine and artificial interaction with respect to listening, reading, speaking and writing are illustrated. For instance, genuine reading can be defined as an information- and curiosity-driven performance whereas artificial reading, or a reading comprehension task, is an exercise-based kind of classroom activity guided by discovering misleading points in the text. The authors aptly notice that the latter prevents readers from appreciating the value of literary texts since social or philosophical issues cannot be solved with yes and no questions (Daszkiewicz et al. 2018: 55). On the other hand, however, they also conclude that, as far as learning to speak is concerned, there is no difference between the kind of a technique used in the classroom and the students' acquisition of this productive skill. Any in-class task provides learners with additional practice, but it does not guarantee the acquisition of the skill.

The first section in Part Two investigates the relationship between listening and learning, allowing the readers to perceive listening both as a target and tool. By examining Learning to Listen and Listening to Learn approaches from sociolinguistic, cognitive and psychological perspectives, the authors intend to present a general view on 
listening. The authors caution against the fallacious conviction that listening does not require any training since it is a receptive skill. Such a stance is particularly misleading as it results in situations in which learning and listening are treated synonymously and there is no distinction made into Learning to Listen and Listening to Learn. Moreover, the writers adopt an intercultural approach to listening, differentiating between low-context cultures, that is Western countries in which the attention is paid to conveying clear and comprehensible messages, and high-context cultures, that is Asian and Middle East countries where speakers focus on shared values and the setting of a conversation.

Section Two is devoted to the discussion of the ability to read. Generally, the written receptive skill entails the lower- and higher-level processing of a text. In the current subchapter the distinction is made into Learning to Read and Reading to Learn approaches. While the former is referred to as a part of language competence, the latter implicates that the skill of reading is used to learn content knowledge. Reading can be also discussed with reference to, for instance, the socio-cognitive model, according to which it is defined as a cognitive ability that takes place in social contexts. The writers discuss three different types of knowledge, that is conceptual, domain and cultural, that can be activated with a view to aiding students' reading comprehension skills. They also analyse the potential of such methodological approaches as CLIL and other techniques, including, among others, Krashen's idea of narrow reading, that can be employed with a view to developing extensive and critical reading skills.

In Section Three speaking is presented as a means of communication and learning. The ability to speak, or oracy is, however, said to be kept extra-curricular, once students have acquired the ability to produce speech. Such a diminishing approach to speaking is questioned since its impact is particularly negative due to the fact that learning does not take place if students do not speak (Daszkiewicz et al. 2018: 115). The authors notice that learners, when faced with questions from a teacher, remain silent. As a result, it is the so-called unuttered reflection that takes place as pupils do not verbalise what they think about teachers' question. It is made clear that the reason behind their unwillingness to communicate is the cult of authorial self-expression since they are afraid to speak if what they want to communicate is not inventive or important enough (Daszkiewicz et al. 2018: 124). Nevertheless, repetitions and readymade expressions are in fact beneficial from the point of view of students' linguistic development. The problem with educational settings is that they are still entrenched in the past, promoting the transformation, not construction of knowledge, as a result of which "students are simply not supposed to have a say before they have familiarised themselves with what is already known." (Daszkiewicz et al. 2018: 127).

In Section Four the role of broadening learners' knowledge and stimulating their creativity is assigned to the productive skill of writing. There are two functions associated with the ability under discussion, that is descriptive-semantic and argumentative-poetic, which allow students to produce self-contained messages free of any paralinguistic or extratextual features. It is highlighted that the progress in writing can be measured by 
means of writers' precision of thinking, or, in other words, their ability to convey what is in their minds. It is stated that foreign language instructors' involvement in writing-oriented tasks is crucial as the teacher-student in-class collaboration is required (Daszkiewicz et al. 2018: 142). Throughout the subchapter the authors provide ten examples of teaching points from such fields as, for example, science, civics, ethics or geology, discussing their usefulness with regard to the development of writing.

Apart from the six sections, there are also two appendices attached to the publication. In the first of them the authors refer to the ERL Association which aims to investigate axiological, psychomotor, affective and cognitive domains from the point of view of the four language skills as well as an individual, society, culture and reality. The authors also enumerate the reasons for studying language skills, provide solutions on how to achieve that and explain the role of language in four educational domains. The second appendix, on the other hand, is of a more practical character. To be more precise, it contains examples of research questions investigating the four language skills from the perspective of man, society, culture and reality, at the same time proving a wide applicability of listening, speaking, reading and writing in various areas of human cognitive activities.

Educational Role of Language Skills is a logically structured seminal work. The theoretical background to the concept of education and language skills encapsulated in Introduction and Part One provides readers with information necessary for the discussion of listening, reading, speaking and writing described in Part Two. Numerous references to an impressive body of evidence from the past research and selected literary investigations concerning the four language skills from the fields of didactics, sociolinguistics and cultural studies guarantee the interdisciplinarity of the authors' explications. What is also particularly useful is the provision of practical ideas for the planning of lessons devoted to the practice of specific skills. More importantly, however, the publication has a serious potential of raising laypeople' awareness of the educational role of language skills, which, as already mentioned, are too often taken for granted in educational settings.

Following "the linguistic turn", according to which it is made evident that language has an influence on how one learns about the world, it is advisable to apply the terms used in language education to other non-language subjects. Owing to the fact that people frequently fail to recognize the connection between their linguistic resources and cognitive growth, language development, which in fact can take place only through the practice of four skills and implementation of glottodidactic concepts, is not prioritized. The authors of Educational Role of Language Skills, however, acknowledge the significance of the quaternary approach, highlighting the fact that even though the four language skills have been widely underrated, they help teachers and learners diagnose their problems in specific fields of study. In other words, it is recommended that language skills ought to be institutionally treated and systematically incorporated into syllabuses, teaching methods or assessment procedures since only education which has been organised around language skills will help both learners and teachers to better track their progress. 